\title{
Preventing cardiac remodeling: The combination of cell-based therapy and cardiac support therapy preserves left ventricular function in rodent model of myocardial ischemia
}

\author{
Suyog A. Mokashi, MD, ${ }^{\mathrm{a}}$ Jian Guan, MD, ${ }^{\mathrm{b}}$ Dahai Wang, MD, PhD, ${ }^{\mathrm{a}}$ Vakhtang Tchantchaleishvili, MD, ${ }^{\mathrm{a}}$ \\ Mark Brigham, BS, ${ }^{\mathrm{d}}$ Stu Lipsitz, PhD, ${ }^{\mathrm{c}}$ Lawrence S. Lee, MD, ${ }^{\mathrm{a}}$ Jan D. Schmitto, MD, PhD, ${ }^{\mathrm{a}}$ \\ R. Morton Bolman III, MD, ${ }^{\mathrm{a}}$ Ali Khademhosseini, $\mathrm{PhD},{ }^{\mathrm{b}, \mathrm{d}}$ Ronglih Liao, $\mathrm{PhD},{ }^{\mathrm{b}}$ and \\ Frederick Y. Chen, MD, $\mathrm{PhD}^{\mathrm{a}}$
}

\begin{abstract}
Objective: Cellular and mechanical treatment to prevent heart failure each holds therapeutic promise but together have not been reported yet. The goal of the present study was to determine whether combining a cardiac support device with cell-based therapy could prevent adverse left ventricular remodeling, more than either therapy alone.
\end{abstract}

\begin{abstract}
Methods: The present study was completed in 2 parts. In the first part, mesenchymal stem cells were isolated from rodent femurs and seeded on a collagen-based scaffold. In the second part, myocardial infarction was induced in 60 rats. The 24 survivors were randomly assigned to 1 of 4 groups: control, stem cell therapy, cardiac support device, and a combination of stem cell therapy and cardiac support device. Left ventricular function was measured with biweekly echocardiography, followed by end-of-life histopathologic analysis at 6 weeks.
\end{abstract}

Results: After myocardial infarction and treatment intervention, the ejection fraction remained preserved (74.9$80.2 \%$ ) in the combination group at an early point (2 weeks) compared with the control group (66.2-82.8\%). By 6 weeks, the combination therapy group had a significantly greater fractional area of change compared with the control group $(69.2 \% \pm 6.7 \%$ and $49.5 \% \pm 6.1 \%$ respectively, $P=.03)$. Also, at 6 weeks, the left ventricular wall thickness was greater in the combination group than in the stem cell therapy alone group (1.79 \pm 0.11 and $1.33 \pm 0.13$, respectively, $P=.02$ ).

Conclusions: Combining a cardiac support device with stem cell therapy preserves left ventricular function after myocardial infarction, more than either therapy alone. Furthermore, stem cell delivery using a cardiac support device is a novel delivery approach for cell-based therapies. (J Thorac Cardiovasc Surg 2010;140:1374-80)

Heart failure is an epidemic affecting roughly 5 million Americans annually. Despite the various pharmacologic and therapeutic advances made in the treatment of ischemic heart failure, the overall mortality remains high. ${ }^{1}$ Fundamentally, heart failure is characterized by the loss of functional cardiomyocytes and the subsequent left ventricular (LV) deterioration that ensues. The pathologic cascades of functional and morphologic changes that occur in the left

From the Division of Cardiac Surgery, ${ }^{\mathrm{a}}$ the Department of Medicine, ${ }^{\mathrm{b}}$ the Center for Surgery and Public Health, ${ }^{\mathrm{c}}$ Brigham and Women's Hospital, Harvard Medical School, Boston, Mass; and the Harvard-Massachusetts Institute of Technology, ${ }^{\mathrm{d}}$ Division of Health Sciences and Technology, Boston, Mass.

Supported by the National Institutes of Health grants, F32HL095275-01A1 (to S.A.M.), RO1HL090862 (to F.Y.C.), RO1HL086967 (to R.L.), RO1HL093148 (to R.L.), R01HL099073 (to R.L.); Brigham and Women's Hospital, Cardiac Surgery Research Fund (to R.M.B.).

Disclosures: None.

Read at the 36th Annual Meeting of The Western Thoracic Surgical Association, Ojai, California, June 23-26, 2010.

Received for publication June 17, 2010; revisions received July 18, 2010; accepted for publication July 30, 2010.

Address for reprints: Frederick Y. Chen, MD, PhD, Division of Cardiac Surgery, Brigham and Women's Hospital, Harvard Medical School, 75 Francis Street, Boston, MA 02115 (E-mail: fchen@ partners.org).

0022-5223/\$36.00

Copyright (C) 2010 by The American Association for Thoracic Surgery doi:10.1016/j.jtcvs.2010.07.070 ventricle are known as ventricular remodeling. Promising surgical and cell-based therapies are being developed to target the start of ventricular remodeling, specifically by treating the ischemic heart after myocardial infarction (MI).

\section{MECHANICAL THERAPY}

One specific feature of ventricular remodeling is the LV dilation and an alteration in the orientation of the cardiac muscle fibers. ${ }^{2}$ Surgical therapy for heart failure has been developed to target the increased LV wall stress associated with ventricular dilation. For example, in ventricular restraint therapy, a prosthetic material is surgically wrapped around the heart to mechanically constrain the ventricles, without restricting ventricular filling. By providing enddiastolic support, ventricular restraint lowers myocardial wall stress and cardiomyocyte overstretch. The data generated from the clinical and animal trials have indicated that lowering myocardial wall stress reverses or halts the remodeling process. ${ }^{3,4}$ Subsequent work has further demonstrated that in addition to decreasing ventricular dilation, a substantial improvement in ejection fraction is observed. ${ }^{5,6}$ 


$$
\begin{aligned}
& \text { Abbreviations and Acronyms } \\
& \begin{aligned}
\mathrm{EF} & =\text { ejection fraction } \\
\% \mathrm{FAC} & =\text { fractional area of change } \\
\mathrm{FS} & =\text { fractional shortening } \\
\mathrm{LV} & =\text { left ventricular } \\
\mathrm{LVID} & =\mathrm{LV} \text { internal diameter } \\
\mathrm{MI} & =\text { myocardial infarction } \\
\mathrm{MSC} & =\text { mesenchymal stem cell }
\end{aligned}
\end{aligned}
$$

\section{CELLULAR THERAPY}

Given the limited regenerative capacity of the heart muscle, the use of exogenous cells to replace lost or damaged cardiomyocytes has enormous therapeutic potential for postinfarction heart failure. Although the ideal cell subtype for transplantation remains controversial, a particular interest has developed in bone marrow-derived mesenchymal stem cells (MSCs). MSCs are highly advantageous for use in cellular therapy because they are readily isolated from adult bone marrow, highly expandible ex vivo, and prevent T-cell maturation. In effect, allogenic MSCs are not rejected by their recipient host. ${ }^{7}$ Ideally, MSCs would replace the lost/damaged cardiomyocytes. Nonetheless, despite conclusive evidence that MSCs replace the lost cardiomyocytes, one beneficial effect of MSCs on LV dysfunction after MI has been attributed to its paracrine effect on cardiomyocytes by secreting various growth factors and cytokines, including granulocytemacrophage colony stimulating factors, stem cell factor 1 , and several interleukins. ${ }^{8,9}$ MSCs provide a unique approach to improve LV function in ischemic heart disease. ${ }^{10,11}$

\section{COMBINATION THERAPY}

To our knowledge, the combination of ventricular restraint therapy and stem cell therapy (combination therapy) in the setting of acute MI has not been previously studied. We hypothesized that combining stem cell therapy and ventricular restraint therapy will preserve cardiac function after MI more than either therapy alone. Thus, we developed a strategy to target heart failure at the underlying mechanical and cellular level. Accordingly, the aim of the present study was to determine whether combination stem cell-ventricular restraint therapy would preserve LV function in a rodent infarction model.

\section{MATERIALS AND METHODS}

\section{Animal Care}

All rats received care in accordance with the guidelines of the "Guide for the Care and Use of Laboratory Animals" published by the National Institutes of Health (NIH publication No. 85-23, National Academy Press, Washington, DC, revised 1996). Female Lewis rats (Charles River, Wilmington, Mass) weighing 175 to $215 \mathrm{~g}$ were used in the present study and housed in a Harvard Medical Area Standing Committee on Animalsapproved animal facility.

\section{Bone Marrow MSC Isolation, Expansion, and Labeling}

In brief, female Lewis rats were killed with an intraperitoneal injection of sodium pentobarbital $(100 \mathrm{mg} / \mathrm{kg})$. The femur and tibia were removed and flushed with cold phosphate-buffered saline. The bone marrow was aspirated with a syringe containing phosphate-buffered saline with $10 \%$ fetal bovine serum and $100 \mathrm{IU} / \mathrm{mL}$ heparin. To separate the bone marrow cells from fat tissue, the solution was filtered through a $70-\mu \mathrm{m}$ filter and centrifuged twice to obtain a cell pellet, as described by YablonkaReuveni and Nameroff. ${ }^{12}$ The pellet was resuspended with complete medium, the cells were seeded with $8 \mathrm{~mL} /$ dish complete medium (Dulbecco's modified Eagles medium supplemented with $15 \%$ fetal bovine serum, $1 \%$ penicillin, $50 \mu \mathrm{g} / \mathrm{mL}$ of ascorbic acid and $2.5 \mathrm{~mL}$ L-glutamine) and cultured in $5 \%$ carbon dioxide, $90 \%$ humidity, and $37^{\circ} \mathrm{C}$. The cells were passaged once until subconfluence was reached. To isolate the MSCs, at first passage, the cells were labeled with green fluorescence protein, and the green fluorescence protein-labeled MSCs were sorted by fluorescenceactivated cell sorting. On the third passage, the sorted MSCs were recultured until confluence was reached and stored in liquid nitrogen until use.

\section{Collaged-Based Scaffold for Cell Transplantation}

In brief, MSCs (stored in liquid nitrogen) were thawed. After confluence was reached, cultured cells were dissociated from the culture dishes with $0.05 \%$ trypsin (Gibco BRL, Grand Island, NY) in phosphate-buffered saline, neutralized with medium, and centrifuged at $2000 \mathrm{rpm}$ for 5 minutes at $4^{\circ} \mathrm{C}$, as described by Tomita and colleagues. ${ }^{13}$ After centrifugation, the cell pellet was resuspended in culture medium at a concentration of $5 \times 10^{5}$. A $50-\mu \mathrm{L}$ cell suspension was used for each scaffold. The scaffolds were made from chondroitin-6-sulfate and had an average pore size of $96 \pm 12 \mu \mathrm{m}$ and $99.5 \%$ porosity; $25 \mu \mathrm{L}$ was loaded on each side of a collagen-based scaffold (5 loading points/side), and the scaffold was stored in medium at $37^{\circ} \mathrm{C}$ for 24 hours before use. Square-shaped scaffolds $(1.0 \mathrm{~cm} \times 1.0 \mathrm{~cm})$, with an average pore diameter of $96 \pm 12 \mu \mathrm{m}$ of $100 \mu \mathrm{m}$ and $99.5 \%$ porosity, were prepared from chondroitin-6-sulfatecross-linked according to a freeze-dry technique.

\section{Ventricular Restraint Device}

The ventricular restraint device used in the present study was a thin plastic sheet wrapped around both ventricles to provide end-diastolic support. The wrap was surgically positioned snugly around both ventricles from the apex to the atrioventricular groove. Each wrap was placed by a single surgeon to provide support without compromising filling and to provide standardization of the wrap placement.

\section{Model}

Each surgical procedure was performed by 1 animal surgeon with extensive experience in rodent surgery. An established and highly reproducible rodent model of MI was used. ${ }^{14}$ In brief, the rats were anesthetized using pentobarbital sodium $(50 \mathrm{mg} / \mathrm{kg}$ intraperitoneally), intubated with a 14-guage angiocatheter and mechanically ventilated with positivepressure ventilation. Standard midline sternotomy and pericardiotomy was performed, and the left coronary artery was identified and ligated with a 6-0 polypropylene suture (Ethicon, Johnson \& Johnson Somerville, NJ) near its origin. The anterior wall of the left ventricle was observed for evidence of blanching, indicating ischemia. If the myocardium did not become increasingly pale, a second ligature was placed more proximally, until a large anterolateral MI comprising approximately $30 \%$ of the left ventricle was noted.

\section{Treatment Groups}

Each rat was randomized into 4 treatment groups: MI, MI and ventricular restraint therapy, MI and stem cell therapy, and MI and combination ventricular restraint-stem cell therapy (Figure 1). 


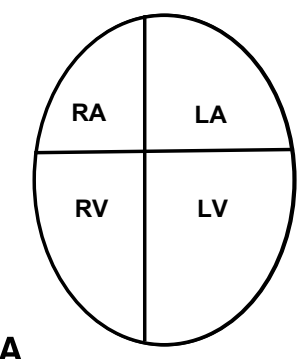

A

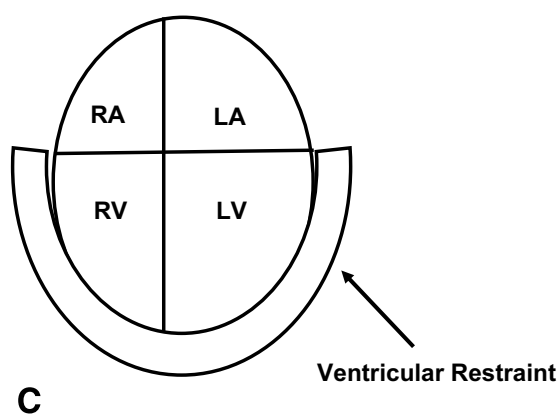

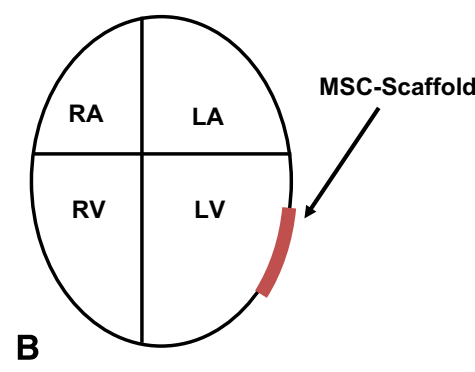

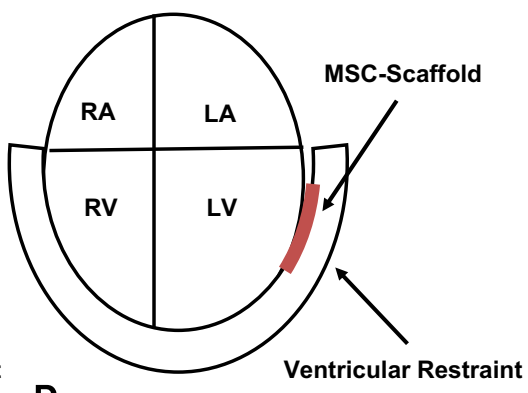

FIGURE 1. Schematic representation of treatment groups. A, Control group; B, stem cell therapy group; C, ventricular restraint group; and D, combination ventricular restraint-stem cell therapy group.

\section{Therapeutic Intervention}

After the MI had been confirmed, the surgeon was informed of the treatment group the rat had been randomly assigned to. In the control group, the chest was immediately closed in layers. In the ventricular restraint group, the ventricular restraint device was wrapped around the heart with 5-0 polypropylene purse-string suture (Ethicon, Johnson \& Johnson) to attain a snug fit, without compromising the ventricular function (Figure 1). In the stem cell group, the MSC-seeded scaffold was sutured to the left ventricle using 6-0 polypropolyene suture at each corner of the scaffold (Johnson \& Johnson; Figure 1). For the combination therapy group (stem cellventricular restraint therapy), the stem cell-seeded scaffold was sutured to the left ventricle with 6-0 polypropolyene suture, followed by placement of the ventricular restraint device (Figure 1). In each rat, the muscle layer and skin incision were closed with 3-0 silk sutures. The rats were monitored for 4 hours postoperatively.

Four treatment groups were MI group $(n=6)$, stem cell therapy group $(\mathrm{n}=5)$, ventricular restraint therapy group $(\mathrm{n}=8)$, and combination stem cell therapy ventricular restraint therapy group $(n=5)$.

\section{Echocardiography}

Transthoracic echocardiography was performed by a separate, blinded investigator on all rats at baseline (1 week before surgery) and 2, 4, and 6 weeks after surgery. A commercially available echocardiographic system equipped with a $30-\mathrm{MHz}$ phased-array transducter was used (VisualSonic Vevo 770, Ontario, Canada). A 2-dimensional mode in the short-axis view of the left ventricle at the level of the papillary muscle was obtained and used to record the M-mode tracings.

The following variables were measured: LV posterior wall thickness, LV internal diameter (LVID), interventricular septum thickness, fractional area of change, fractional shortening (FS), and ejection fraction (EF). All measurements were averaged for three cardiac cycles and were performed by an experienced technician blind to the treatment group.

\section{Histologic and End of Life Analysis}

At 6 weeks after surgery, the rats were killed with pentobarbital $(50 \mathrm{mg} /$ $\mathrm{kg}$ ). The hearts were quickly excised and perfused with Krebs-Henseleit buffer (mmol/L: $\mathrm{NaCl}, 118 ; \mathrm{KCl}, 4.7 ; \mathrm{KH}_{2} \mathrm{PO}_{4}, 1.2 ; \mathrm{CaCl}_{2}, 2.5 ; \mathrm{MgSO}_{4}$,
1.2; $\mathrm{NaHCO}_{3}, 25$; and glucose, 11; $\mathrm{pH} 7.4$ ) followed by fixation with neutralized $10 \%$ formaldehyde. Each heart was weighed, tibia length measured and liver/lung wet and dry weight (48 hours of dehydrating) were measured.

The left ventricle was cut transversely from base to apex into 4 equal regions $-5-\mu \mathrm{m}$ slices of each region were embedded in paraffin and stained with hematoxylin and eosin and Masson's trichrome.

\section{Infarct Percentage Analysis}

Hematoxylin and eosin-stained sections were analyzed for infarct percentage analysis. The epicardial and endocardial surface areas of each section were measured by the techniques of Pfeffer and colleagues. ${ }^{15}$ The epicardial and endocardial circumference, and circumference occupied by the infracted wall were traced onto a transparency and quantified using digital planimetry software in a blinded manner. Infarct size was expressed as percentage of the total $\mathrm{LV}$ circumference.

\section{Statistic Analysis}

Data are given as the mean \pm standard error. To compare the echocardiographic parameters over time between treatment groups, we used a version of repeated measures analysis of variance that accounts for the correlation within subjects using an autoregressive correlation model (SAS PROC MIXED, SAS Institute, Cary, NC). To compare echocardiographic parameters at a given time between treatment groups, we used a $t$ test derived from the same repeated measures analysis of variance. To compare echocardiographic parameters from baseline to 6 weeks within each group, we used a paired $t$ test. Differences were considered significant at $P \leq .05$.

\section{Responsibility}

The authors had full access to the data and take full responsibility for their integrity. All authors have read and agree to the report as written.

\section{RESULTS}

Of the 60 rodents that underwent a MI/therapeutic intervention procedure, 24 survived and were included in the analysis. 

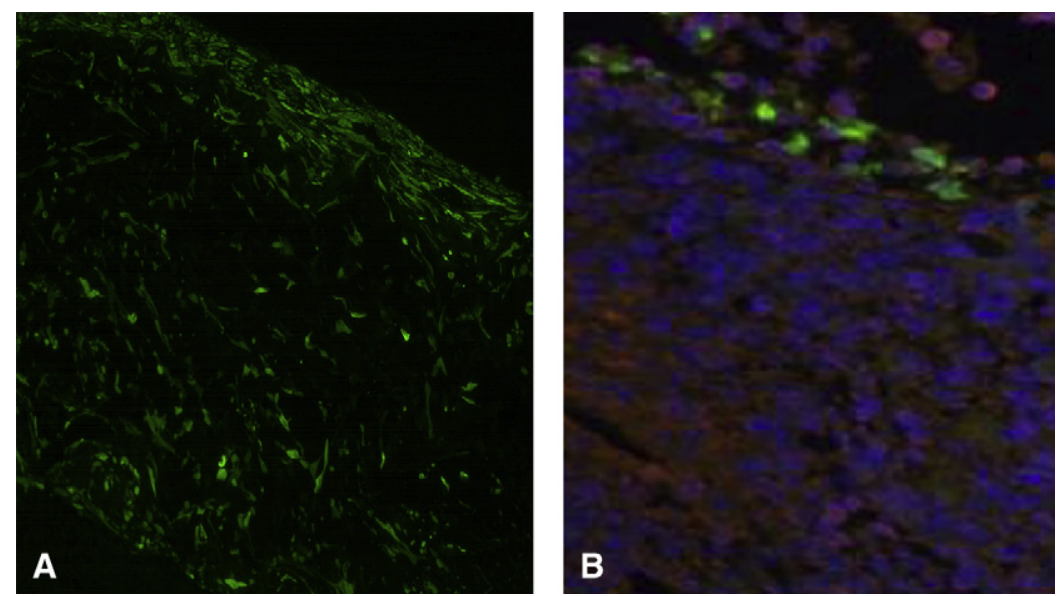

FIGURE 2. Evidence of effective mesenchymal stem cell transplantation at 72 hours after transplant. In vivo characterization of A, mesenchymal stem cells (MSCs) on stem cell scaffold positioned on infarcted myocardium and B, MSCs translocated within infracted myocardium. Paraffin-embedded slides underwent immunofluorescence staining with antibodies $46^{\prime}$-diamidino-2-phenylindole-2 $\mathrm{HCl}$ and anti-green fluorescence protein.

\section{Identification of MSCs Transplantation}

To confirm that MSCs were effectively loaded on a collagen-based scaffold and transplanted within the ischemic myocardium, paraffin-embedded hearts were immunohistochemically stained with monoclonal antibodies against antigreen fluorescence protein and diamidino-2-phenylindole. The maximal number of MSCs was found concentrated in the middle of the collagen-based scaffold (Figure 2, A) and had successfully been translocated within the ischemic myocardium after transplantation (Figure 2, $B$ ).

\section{Infarction Percentage}

The percentage of LV infarction area was appropriately equivalent in the combination group compared with the control group at 6 weeks $(26 \% \pm 12 \%$ versus $31 \% \pm$ $6 \%, P=0.39$, Figure 3, A). Furthermore, in the stem cell group, the percentage of LV infarction was identical to the control group $(32 \% \pm 8 \%$ versus $31 \% \pm 6 \%, P=.39)$. This implies that any functional/morphologic differences observed among the treatment groups could not be attributed to a difference in infarction size. A representative LV sectioned into 4 segments from apex to base and stained with hematoxylin and eosin is illustrated in Figure 3, B. The ventricular segment that stained blue represents the infarction area.

\section{Morphologic Assessment}

Cardiac morphology was studied according to the LV chamber size (LVID) and LV wall thickness (average of LV posterior wall and interventricular septum at diastole), which was determined by echocardiography. At 6 weeks, the LVID was less in the stem cell group compared with the control $(6.2 \pm 1.3 \mathrm{~mm}$ versus $7.2 \pm 0.8 \mathrm{~mm})$. The LVID was equal between the control, restraint group, and combination groups $(7.2 \% \pm 0.8 \%$ versus $7.7 \% \pm 1.1 \%$ versus $7.3 \% \pm 0.9 \%$ ). Regarding wall thickness, at 6 weeks, the LV wall thickness was greater with combination group $(1.8 \pm 0.3)$ compared with stem cell group alone $(1.4 \pm 0.2)(P=.02)$.
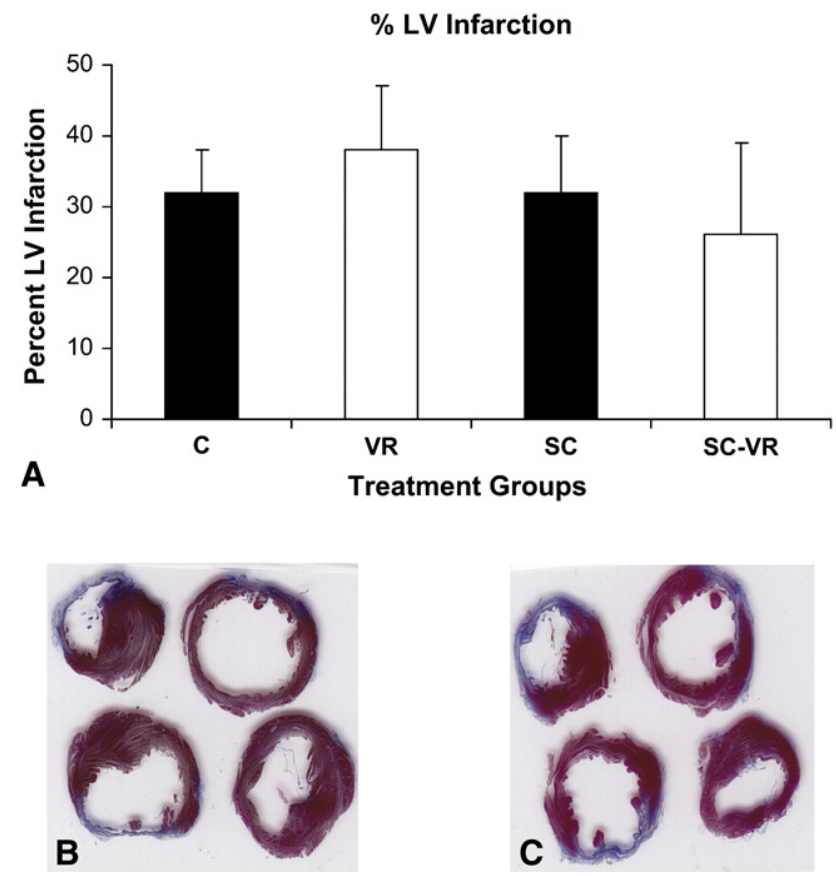

FIGURE 3. Percentage of left ventricular infarction area. A, Histologic examination of percentage of left ventricular (LV) infarction by trichrome staining. Quantitative analysis showed 5\% lower LV infarction percentage in combination therapy group compared with control group $(P=.39)$. $C$, control; $S$, stem cell; $V R$, ventricular restraint; $S C$ - $V R$, stem cellventricular restraint. Representative samples from typical left ventricle divided into 4-equal sections from base to apex from B, Stem cell therapy group and $\mathrm{C}$, ventricular restraint group. Blue region represents area of infarction. 

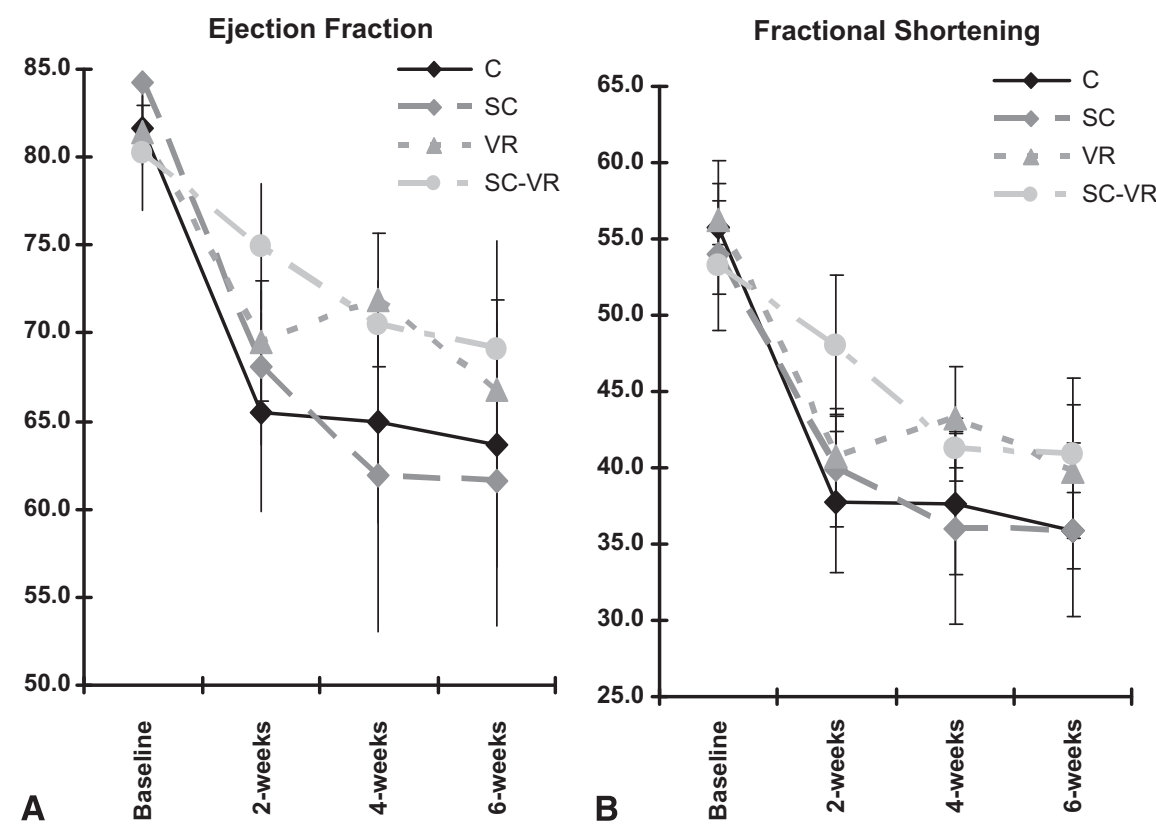

FIGURE 4. A, Ejection fraction (EF) and B, fractional shortening (FS) as a function of time. Values expressed as mean of each treatment group at specific time. $C$, control; $S C$, stem cell; $V R$, ventricular restraint; $S C$-VR, stem cell-ventricular restraint. Values expressed as mean \pm standard error.

\section{Functional Assessment}

At baseline, the ejection fraction (EF), fractional shortening (FS), and fractional area change (\%FAC) at the midpapillary level were similar among each treatment group.

At 2 weeks after MI and intervention, a mean absolute decrease in EF from baseline was observed in the control group (Figure 4, A). In contrast, the $\mathrm{EF}$ was preserved in the combination group (baseline $80.2 \% \% \pm 2.7 \%$ versus 2 weeks, $74.9 \% \pm 5.6 \%, P=\mathrm{NS}$, Figure $4, A$ ). At 2 weeks after infarction, a large difference was seen in the percentage decrease in $\mathrm{EF}$ from baseline in the control and combination groups $(20.0 \%$ versus $6.6 \%)$.

From 2 to 4 weeks after MI and intervention, the EF in the control group did not change and remained decreased $(66.2 \% \pm 15 \%$ versus $65.4 \% \pm 15.4 \%$, Figure $4, A)$. Appropriately, the EF in the combination group remained the same; however, this effect was beneficial because the $\mathrm{EF}$ was preserved $(74.9 \% \pm 8.9 \%$ versus $70.5 \% \pm$ $6.1 \%$, Figure $4, A)$. By 6 weeks after MI, the EF was similar between the control and combination group $(63.7 \% \pm$ $3.4 \%$ versus $69.1 \% \pm 4.2 \%, P=.35$ ). However, a statistically significant difference was seen in the \%FAC between the control $(69.2 \% \pm 6.7 \%)$ and combination group $(49.5 \% \pm 6.1 \% ; P=.04)$.

At 2, 4, and 6 weeks, the EF, FS, and \%FAC were greater in the combination group than in the stem cell group itself. Moreover, the EF of the combination group and restraint group were similar at 4 and 6 weeks $(70.5 \% \pm 3.7 \%$ versus $72.4 \% \pm 3.0 \%, P=.72$ and $69.1 \% \pm 6.0 \%$ versus $67.6 \% \pm 4.3 \%, P=.8$, respectively).

\section{End of Life Analysis}

To assess the systemic response to heart failure, the heart, left ventricle, tibia length ratio, and liver/lung wet/dry weights were measured. At the end of life inspection, the hearts from the various treatment groups were indistinguishable from the control MI group. The LV weight, heart weight/tibia length, and heart weight/body weight were identical in all groups. Moreover, the change in both the lung and liver at 48 hours, the wet/dry ratio were similar in all groups.

\section{DISCUSSION}

Stem cell therapy and ventricular restraint therapy have each been shown to improve ventricular function in clinical and animal heart failure models, suggesting, at least in part, that each reverses the remodeling process. However, combining the 2 therapies had yet to be studied. We have shown that combination stem cell-ventricular restraint therapy preserves cardiac function after MI. In addition, ventricular restraint attenuates the beneficial functional and morphologic effects of stem cell therapy. Combination stem cellventricular restraint therapy preserved the wall thickness more than stem cell therapy alone.

Heart failure is regarded as an irreversible and progressive disease marked by ventricular enlargement, mechanical insufficiency, and pump dysfunction. The initial insult to pump function evokes compensatory mechanisms aimed at maintaining cardiac output-ventricular dilation, cardiomyocyte hypertrophy, and neurohumoral activation. ${ }^{16}$ Although early on the compensatory response preserves 
ventricular function, in the long run, an adverse remodeling process results in deleterious LV structural and functional changes-ventricular remodeling. Ultimately, end-stage disease develops and the heart is unable to maintain systemic perfusion required for metabolizing tissues. Specifically, ventricular remodeling is characterized by an alteration in LV function and structure-involving both the infarcted and the noninfarcted ventricular topography. Several pathologic processes contribute to LV dilation: thinning and lengthening of infarct and border zone regions (infarct expansion), myocardial wall stress, and infarct healing. These multiple factors contributed at different stages, from the point of infarction until the development of ventricular dilation. Pfeffer and colleagues ${ }^{17}$ proved that the most effective method to prevent or minimize ventricular remodeling after $\mathrm{MI}$ is to limit the initial insult. ${ }^{18}$ Accordingly, our laboratory has developed a therapeutic intervention to halt ventricular remodeling at its inception, by treating the ischemic heart with both cellular and mechanical-based therapy.

The present study has demonstrated that combination therapy beneficially preserves cardiac function after MI. The combination group had greater EF, FS, and \%FAC at 2,4 , and 6 weeks after myocardial ischemia compared with the control group. However, the findings at 6 weeks warrant discussion. The LVID was similar between the combination and control groups. One possible explanation is that a paracrine effect from the MSCs was short lived. As suggested by Dai and colleagues, ${ }^{19}$ the beneficial effects of stem cell therapy on the cardiac structure might not be apparent by 6 weeks. The goal of cellular therapy-to regenerate lost myocardium through the differentiation of stem cells into cardiomyocytes, might take longer than expected. Their results have shown that of the transplanted MSCs that survived in infarcts, the expression of muscle markers required up to 6 months. ${ }^{19}$ This was further supported by Davani and colleagues, ${ }^{20}$ who noted that MSCs fail to express major gap junction proteins of the intercalated disks of cardiomyocytes at 6 weeks. This provides additional evidence that terminal differentiation of MSCs might require long periods. ${ }^{20}$ At the 4- and 6-week points, the EF of the restraint device was similar to the combination group, further supporting a potential paracrine effect role of the MSCs. Moreover, no difference was found in the infarct percentage area in the groups with MSCs.

At present, the exact window of treatment to prevent or reverse the remodeling process is unknown. The timing and route of stem cell administration to the infracted myocardium are important variables for successful cellular therapy. We believe the direct application of MSCs to the infracted and border zone areas of the myocardium provides an optimal route for cell transplantation. Hale and colleagues $^{21}$ compared MSC survival when transplanted immediately after MI using either intravenous administration or direct myocardial injection to the infarction. The investigators had shown that $15 \%$ of labeled cells remained in the left ventricle 1 week after direct myocardial injection compared with $<1 \%$ after intravenous injection. Furthermore, although MSC transplantation has shown a benefit after acute MI, the optimal timing for therapeutic intervention is unknown. ${ }^{22}$ Using a rodent MI model, Jiang and colleagues $^{23}$ compared the effects of MSC transplantation at 1 hour, 1 week, and 2 weeks. They found that MSC transplantation at 1 week compared with 1 hour showed an improvement in cardiac function (FS and $\mathrm{EF}$ ), apoptosis, and angiogenesis. ${ }^{23}$ We have, therefore, concluded direct stem cell transplantation using a scaffold provides an effective delivery method, although the optimal timing remains unknown.

At 2 weeks after MI and therapeutic intervention, a clear functional advantage existed in the combination stem cellventricular restraint therapy group compared with the control group. However, this beneficial effect became less clear by 6 weeks. One possibility was that the stem cells became damaged by 6 weeks. To preserve stem cell function, as suggested by Davis and colleagues, ${ }^{24}$ an optimal stem cell microenvironment should be used that promotes cell survival and organization. Specifically, a peptide-based scaffold can be engineered to minimize the profound inflammatory response after MI and also produce beneficial growth factors/signals for cardiomyocyte recruitment. ${ }^{24}$

One surprising finding in the present study was the beneficial effect of ventricular restraint on cellular therapy. In terms of EF, FS, and endocardial area change, the rats treated with combination therapy showed a greater improvement in each of the 3 parameters compared with stem cell therapy alone. Therefore, ventricular restraint improves the effectiveness of stem cell therapy. Future studies determining the exact mechanism of combination therapy are needed.

In ventricular restraint therapy, a prosthetic wrap provides circumferential diastolic support, thereby preventing adverse ventricular remodeling. Once implanted, the wrap is constant and unchanging, even as the heart undergoes reverse remodeling. Consequently, no rational criteria exist to optimize therapy in a physiologic manner (i.e., no way method is available to maintain a constant level of restraint even as the size of the heart decreases and the wrap becomes effectively looser). We believe that this nonmeasurable and nonadjustable nature of current devices is the greatest limitation of current restraint technology. Our laboratory therefore developed an adjustable, fluid-filled polyurethane balloon capable of quantitatively applying restraint to the entire ventricular surface. ${ }^{3}$ We then showed that the application of this device to both ventricles with periodic adjustments to maintain the level of restraint was associated with significant reductions in end-diastolic volume and increases in $\mathrm{EF}$ in an ovine model of heart failure. ${ }^{3}$ These changes were associated 
with decreases in transmural pressure and myocardial oxygen consumption, providing a theoretical basis for how ventricular restraint produces reverse LV remodeling in heart failure. Although difficult to use in a rodent model, future studies with adjustable ventricular restraint in a large animal model of cardiomyopathy are needed.

A second limitation was that although 60 rats underwent the MI/treatment intervention, 24 rats survived the operation. The overall number of rats per group could have led to a bias in our conclusion. However, the overall trend differences in morphology and function between the treatment groups are apparent.

Treating heart failure presents a daunting challenge for cardiovascular specialists. Current therapeutic strategies have focused on either stem cell therapy or mechanical (ventricular restraint therapy). However, any truly successful treatment plan must address the underlying problem - cellular death/dysfunction and altered ventricular mechanics-or the effectiveness will ultimately be inadequate.

\section{CONCLUSIONS}

The results of the present study have demonstrated the therapeutic potential of combining stem cell therapy with ventricular restraint therapy.

\section{References}

1. Jessup M. Aldosterone blockade and heart failure. N Engl J Med. 2003;348: 1380-2.

2. Levin HR, Oz MC, Chen JM, Packer M, Rose EA, Burkhoff D. Reversal of chronic ventricular dilation in patients with end-stage cardiomyopathy by prolonged mechanical unloading. Circulation. 1995;91:2717-20.

3. Ghanta RK, Rangaraj A, Umakanthan R, Lee L, Laurence RG, Fox JA, et al. Adjustable, physiological ventricular restraint improves left ventricular mechanics and reduces dilatation in an ovine model of chronic heart failure. Circulation. 2007;115:1201-10.

4. Konertz WF, Shapland JE, Hotz H, Dushe S, Braun JP, Stantke K, et al. Passive containment and reverse remodeling by a novel textile cardiac support device. Circulation. 2001;104(12 Suppl. 1):I270-5.

5. Oh JH, Badhwar V, Mott BD, Li CM, Chiu RC. The effects of prosthetic cardiac binding and adynamic cardiomyoplasty in a model of dilated cardiomyopathy. J Thorac Cardiovasc Surg. 1998;116:148-53.

6. Acker MA. Clinical results with the Acorn cardiac restraint device with and without mitral valve surgery. Semin Thorac Cardiovasc Surg. 2005;17:361-3.
7. Majumdar MK, Thiede MA, Mosca JD, Moorman M, Gerson SL. Phenotypic and functional comparison of cultures of marrow-derived mesenchymal stem cells (MSCs) and stromal cells. J Cell Physiol. 1998;176:57-66.

8. Tse WT, Pendleton JD, Beyer WM, Egalka MC, Guinan EC. Suppression of allogeneic T-cell proliferation by human marrow stromal cells: Implications in transplantation. Transplantation. 2003;75:389-97.

9. Di Nicola M, Carlo-Stella C, Magni M, Milanesi M, Longoni PD, Matteucci P, et al. Human bone marrow stromal cells suppress T-lymphocyte proliferation induced by cellular or nonspecific mitogenic stimuli. Blood. 2002;99:3838-43.

10. Le Blanc K, Tammik L, Sundberg B, Haynesworth SE, Ringdén O. Mesenchymal stem cells inhibit and stimulate mixed lymphocyte cultures and mitogenic responses independently of the major histocompatibility complex. Scand J Immunol. 2003;57:11-20.

11. Orlic D, Kajstura J, Chimenti S, Jakoniuk I, Anderson SM, Li B, et al. Bone marrow cells regenerate infarcted myocardium. Nature. 2001;410:701-5.

12. Yablonka-Reuveni Z, Nameroff M. Skeletal muscle cell populations: Separation and partial characterization of fibroblast-like cells from embryonic tissue using density centrifugation. Histochemistry. 1987;87:27-38.

13. Tomita S, Li RK, Weisel RD, Mickle DA, Kim EJ, Sakai T, et al. Autologous transplantation of bone marrow cells improves damaged heart function. Circulation. 1999;100(19 Suppl.):II247-56.

14. Müller-Ehmsen J, Peterson KL, Kedes L, Whittaker P, Dow JS, Long TI, et al. Rebuilding a damaged heart: Long-term survival of transplanted neonatal rat cardiomyocytes after myocardial infarction and effect on cardiac function. Circulation. 2002;105:1720-6.

15. Pfeffer MA, Fletcher PJ, Braunwald E. Progressive ventricular remodeling in rat with myocardial infarction. Am J Physiol. 1991;260(5 Pt 2):H1406-14.

16. Sabbah HN, Sharov VG, Gupta RC, Mishra S, Rastogi S, Undrovinas AI, et al. Reversal of chronic molecular and cellular abnormalities due to heart failure by passive mechanical ventricular containment. Circ Res. 2003;93:1095-101.

17. Pfeffer MA, Braunwald E. Ventricular remodeling after myocardial infarction: Experimental observations and clinical implications. Circulation. 1990;81: 1161-72.

18. Zardini P, Marino P, Golia G, Anselmi M, Castelli M. Ventricular remodeling and infarct expansion. Am J Cardiol. 1993;72:98G-106G.

19. Dai W, Hale SL, Martin BJ, Kuang JQ, Dow JS, Wold LE, et al. Allogeneic mesenchymal stem cell transplantation in postinfarcted rat myocardium: Short- and long-term effects. Circulation. 2005;112:214-23.

20. Davani S, Marandin A, Mersin N, Royer B, Kantelip B, Hervé P, et al. Mesenchymal progenitor cells differentiate into an endothelial phenotype, enhance vascular density, and improve heart function in a rat cellular cardiomyoplasty model. Circulation. 2003;108(Suppl. 1):II253-8.

21. Hale SL, Dai W, Dow JS, Kloner RA. Mesenchymal stem cell administration at coronary artery reperfusion in the rat by two delivery routes: A quantitative assessment. Life Sci. 2008;83:511-5.

22. Imanishi Y, Saito A, Komoda H, Kitagawa-Sakakida S, Miyagawa S, Kondoh H, et al. Allogenic mesenchymal stem cell transplantation has a therapeutic effect in acute myocardial infarction in rats. J Mol Cell Cardiol. 2008;44:662-71.

23. Jiang CY, Gui C, He AN, Hu XY, Chen J, Jiang Y, et al. Optimal time for mesenchymal stem cell transplantation in rats with myocardial infarction. J Zhejiang Univ Sci B. 2008;9:630-7.

24. Davis ME, Motion JP, Narmoneva DA, Takahashi T, Hakuno D, Kamm RD, et al. Injectable self-assembling peptide nanofibers create intramyocardial microenvironments for endothelial cells. Circulation. 2005;111:442-50. 